\title{
PRESENTACIÓN:
}

\section{LA HISTORIA DE LOS TEXTOS CIENTÍFICOS EN LA MIRADA DEL FILÓLOGO Y DEL CIENTÍFICO}

\author{
J. M. Blecua, J. Gutiérrez Cuadrado, J. A. Pascual
}

(Coords.)

Nos parece especialmente relevante que un investigador como José Luis Peset, acostumbrado a colaborar con colegas de diferentes especialidades, nos haya invitado a seleccionar varios trabajos de historia de la lengua, relacionados con textos científicos, para publicarlos en Asclepio. Es necesario agradecerle que la revista acoja en sus páginas a un grupo de filólogos; sobre todo, merece la pena destacar la oportunidad de la invitación, pues el colaborar entre historiadores de la ciencia y de la lengua resulta esencial para comprender mejor algunos aspectos de nuestro pasado cultural y lingüístico y, probablemente, de la propia historia de nuestra ciencia.

La antología que presentamos nace con unos límites externos, el espacio que la Revista tan generosamente ha puesto a nuestra disposición; y con otros internos, el horizonte de la ciencia que atrae actualmente la atención de los filólogos. Parece aconsejable que nos refiramos brevemente a esta última cuestión antes de comentar los trabajos que hemos elegido. Así los lectores no se perderán en un piélago de suposiciones.

Posiblemente les resulten chocantes algunos aspectos de estos trabajos a los historiadores de la ciencia, pues disponen ellos de más información sobre cualquiera de los temas tratados, así como de planteamientos históricos más matizados que muchos de los nuestros. ¿Qué ventaja proporciona — podrían pensar - mirar en un espejo la imagen borrosa de lo que conocemos mejor de otra manera? 
Si los historiadores de la ciencia se dejaran arrebatar por esta primera impresión, perderían la oportunidad de conocer, aunque fuera desdibujadamente, algunos aspectos históricos que sus propios intereses e instrumentos dejan en cierta penumbra, cuando no en completa oscuridad. La lengua, ciertamente, puede no suponer más que un modesto apoyo en una investigación histórica; pero no se debe olvidar que, a veces, la diferencia entre los éxitos y fracasos depende de esos detalles modestos. Puesto que en la lengua todo son diferencias y todos los términos son históricos, la aportación elemental, pero imprescindible, de la filología consiste en ofrecer el cañamazo donde deben bordarse las apreciaciones de significado dignas de tal nombre. Por poner un ejemplo relevante, ¿se puede verdaderamente hablar de los términos relacionados con los engranajes, confundiendo en un presente ahistórico, todas las capas léxicas de las diversas épocas, espacios y lenguas que han contribuido a configurar la terminología actual de las máquinas en español?

Es evidente que lo ideal sería que los filólogos se acercaran a la lengua de la ciencia en colaboración con los historiadores de cada especialidad. Sin embargo, hasta que entre todos hagamos posible que las cuestiones lingüísticas sean algo más que un envoltorio formal - a veces levemente engorroso- de los hechos significativos y mucho más que una norma educada que debe manejarse en los discursos públicos con el consejo de algún colega humanista, bueno será que examinen los colegas de historia de la ciencia estos trabajos con simpatía, con indulgencia y con interés. Si se acercaran a estas páginas con simpatía, descubrirían el esfuerzo que están haciendo otros especialistas para conocer sus trabajos y digerirlos, y se sorprenderían de los admiradores desconocidos que tienen. Si utilizaran la indulgencia en sus juicios, comprenderían que la idea que los filólogos tienen de la ciencia quizá no coincida, todavía, con la de los propios historiadores, pero dista ya mucho de la visión tradicional que lucían las personas de letras. Si leyeran los trabajos con interés, advertirían que encierran cuestiones dignas de estudio y que la colaboración interdisciplinar sería buen remedio para alcanzar objetivos más ambiciosos en las respectivas disciplinas.

Los autores de esta antología muestran cómo la historia de la lengua de la ciencia no se agota con las simples listas de neologismos relacionados con los objetos que llegan de otros países; a la vez que saben adentrarse por una serie de problemas complejos, de una manera que puede calificarse de todo menos de ingenua. Incluso, en algunos casos, la presentación de un esquema de trabajo para aproximarse a la especialidad estudiada, sirve casi como algoritmo para que otros jóvenes filólogos se acerquen a otras especialidades o campos de la ciencia. Estos estudios no solo ofrecen, pues, resultados y panoramas novedo- 
sos en la historia de la lengua española, sino que, además, exponen con claridad aspectos metodológicos que podrán, más tarde, afinarse, discutirse, etc.

Los filólogos e historiadores de la lengua que se dedican a estudiar el lenguaje científico - y de una manera no poco refinada - alcanzan ya una cifra no despreciable en España: trabajan en diversas universidades (La Coruña, Salamanca, Alcalá, Zaragoza, País Vasco, Murcia, Tarragona, Lérida, Castellón, varias de Barcelona, etc.). Por ello, como no son tan pocos, ni sus orientaciones homogéneas, hemos tenido que prescindir de varios autores, de bastantes páginas y de algunas cuestiones interesantes y reducir esta antología a representantes de distintos grupos de investigación, interrelacionados entre sí, que se han preocupado por los textos científicos desde hace años. Con ello puede, quizá, haberse perdido variedad, pero queda reflejada una cierta coherencia en los planteamientos. Por otro lado, se han seleccionado, sobre todo, trabajos relacionados con la historia moderna, tanto de técnicas nuevas como de otras que se renovaron en el siglo XIX, pero pertenecían a una larga tradición. Nadie se extrañará, teniendo en cuenta la atención que ha merecido la química, que hayamos seleccionado dos artículos, uno más general y otro más analítico. Tenemos la suerte, además, de poder contar con un artículo de Bertha Gutiérrez, una de las mejores conocedoras peninsulares de las cuestiones de lengua y ciencia. Y nos pareció conveniente aprovechar el panorama que presenta María Jesús Mancho de la lengua de la ciencia en el Siglo de Oro español, tan diferente de aquel que trazaba Vossler en sus mejores tiempos, cuando comentaba que lo propio de los españoles era el arte y la literatura, porque la ciencia les resultaba extraña. Por fin, hemos creído aconsejable mostrar las dificultades específicas que encierra el mundo tan complejo de la minería, de tanta importancia en las relaciones entre la Corona de Castilla y las Indias.

En ningún momento hemos creído que solo exista una manera de estudiar los problemas y las dificultades que nos plantean estos textos. Por ello, no será pequeña nuestra satisfacción si la acogida que nos ha brindado Asclepio a los filólogos sirve para un mayor acercamiento entre quienes observamos la realidad, bien desde las palabras, bien desde las cosas. 